\title{
Facial Palsy after Carotid Endarterectomy \& Difficult Intubation during Subsequent CABG Surgery: An Impact of the Cranial Nerve Injury on Airway Management
}

Won K. Chee

Assistant Professor, Department of Anesthesiology, Montefiore Medical Center \& Albert Einstein College of Medicine, 111 East 210th Street, Bronx, New York, 10467 USA.

\begin{abstract}
Cranial nerve injuries can occur during carotid endarterectomy from extensive dissection and prolonged retraction. The nerve injuries can impact both the airway reflex and the anatomical contour to cause a difficulty with subsequent airway management for the anesthesiologists. A careful examination of the airway after the carotid procedure is critical for recognizing the subtle signs of cranial nerve injuries.
\end{abstract}

*Corresponding Author:

Won K. Chee, M.D., M.B.A,

Assistant Professor, Department of Anesthesiology, Montefiore Medical Center \& Albert Einstein College of Medicine, 111 East 210th Street, Bronx, New York, 10467 USA.

E-Mail: WCHEE@montefiore.org

Received: February 12, 2015

Accepted: March 02, 2015

Published: March 04, 2015

Citation: Won K. Chee (2015) Facial Palsy after Carotid Endarterectomy \& Difficult Intubation during Subsequent CABG Surgery: An Impact of the Cranial Nerve Injury on Airway Management. Int J Anesth Res. 3(2), 85-86. doi: http://dx.doi.org/10.19070/2332-2780-1500021

Copyright: Won K. Chee ${ }^{\odot} 2015$. This is an open-access article distributed under the terms of the Creative Commons Attribution License, which permits unrestricted use, distribution and reproduction in any medium, provided the original author and source are credited.

\section{Introduction}

A facial droop following carotid endarterectomy (CEA) could be the result of central nerve dysfunction such as a cerebrovascular accident (CVA) or a peripheral nerve problem like a facial nerve injury. It is well known to anesthesiologists that thromboembolic event during the procedure is a major complication, a stroke, in which case an involvement of the contralateral hemiparesis is also likely. Findings from CT studies and physical examination are helpful in establishing the diagnosis. Less familiar to anesthesiologists are the complications of cranial nerve injuries from the retraction and dissection of the neck area. Cranial nerve injuries can complicate the postoperative course of care and management. The case report describes a patient whose airway anatomy and reflex were apparently affected by the cranial nerve injuries during CEA. This change was recognized as a new difficulty with intubation during the subsequent CABG surgery.

\section{Case Description}

A 75-year-old female was scheduled for right CEA and CABG surgery (on two separate dates). Her past medical history was significant for recent MI, hypertension, diabetes mellitus type 2, hypercholesterolemia and possible obstructive sleep apnea (STOP-Bang score 4). Past surgical history included recent coronary angioplasty and laparoscopic cholecystectomy under general anesthesia without any anesthetic complications. The airway evaluation revealed Mallampati 3 classification. (Height: 5 feet 1 inch, Weight: 142 pounds, BMI: 26.8) First, the patient underwent right CEA under general anesthesia. Intubation was uneventful; the vocal cords were easily visualized under direct laryngoscopy using a MAC 3 blade. However, the surgical procedure took over 6 hours due to a technical difficulty associated with the location and the extent of the lesion ( $99.9 \%$ occluded). Postoperatively, the patient's right side of the face drooped slightly. Also, her speech sounded slightly slurred although her voice was not hoarse. Her tongue pointed midline when protruded.

As the CT scan study was negative for any cerebral hemorrhage or infarct, $\mathrm{CABG}$ surgery proceeded 2 days later. When the same anesthesiologist performed direct laryngoscopy with a MAC 3 blade, however, the vocal cords could not be visualized at all. The Glidescope was needed for successful intubation. One week after the surgery, the patient required reintubation and mechanical ventilation due to pneumonia and respiratory failure. Another physician performed direct laryngoscopy, and visualization of the vocal cords was not difficult. Later, diagnostic studies showed evidences of the abnormal swallowing reflex with micro-aspiration. The chest $\mathrm{x}$-ray was consistent with aspiration pneumonitis. As a result, limitation of oral intake and vocal cord exercise were implemented for recovery.

\section{Discussion}

Various studies in literature, particularly in surgery, show cranial nerve injuries after CEA are relatively common and mostly transient [1]. Also, a literature review found cranial nerves VII, X and XII were commonly injured while IX and XIwere not [2]. In one prospective study of 200 patients, $12.5 \%$ of the patients developed transient nerve injuries that resolved within 6 months in almost all cases. Most commonly involved nerves were the hy- 
poglossal nerve and the recurrent laryngeal nerve from the vagus nerve [3]. In another study of 183 patients, $14.2 \%$ of the patients were identified with the problem. Again, the recurrent laryngeal nerve and the hypoglossal nerve were mainly affected [4].

When the procedure was performed under cervical plexus block, the most common injuries occurred on the marginal mandibular branch of the facial nerve [5]. Overall, Peripheral facial nerve injury has been reported in 1-4\% of CEA and is related to surgical retraction and/or tissue edema [6-8]. It has been speculated that direct infiltration of the local anesthetics at the surgical site inadvertently blocked the facial nerve [9].

Some injuries to recurrent laryngeal nerve required the longest period for full recovery or remained permanent in rare cases. For instance, 2 patients with the recurrent laryngeal nerve injury required a prolonged recovery period between 2.5 to 4 years [3].

Manifestation of a cranial injury is closely associated with the particular nerve dysfunction. A facial nerve (XII) injury leads to flattening of the mandibular area; a glossopharyngeal nerve (IX) and a vagal $(\mathrm{X})$ injury can lead to dysphagia, dysarthria, recurrent aspiration and respiratory failure. A hypoglossal nerve (XII) injury is identified by ipsilateral deviation of the tongue and impairment of swallowing and speech as well.

It is reasonable to anticipate some changes in airway anatomy with tissue edema resulting from surgical retraction and dissection. Furthermore, the motor cranial nerve injuries may alter the muscle tone and the contour of the airway anatomy. Consequently, the airway management may become difficult from the change. Finally, abnormal airway reflex from cranial nerve dysfunction can lead to airway obstruction, aspiration pneumonitis and respiratory failure.

In this case, injuries to the mandibular branch of the facial cranial nerve and the glossopharyngeal nerve were strongly suspected given the facial droop and the subtle changes noted with both swallowing and speech. The hypoglossal nerve injury was unlikely as the protruding tongue was not deviating ipsilaterally. Eventually, she required intubation and mechanical ventilation after developing pneumonia and respiratory failure

\section{Conclusion}

In conclusion, cranial nerve injuries may impact both function and anatomy of the airway. Both tissue edema and the cranial nerve injuries may impact the anatomy and function of the airway, making it difficult for intubation and increasing the risk of respiratory complications. A careful re-examination of the airway is warranted for the patients after CEA for cranial nerve injuries.

\section{References}

[1]. Forssell C, Kitzing P, Bergqvist D (1995) Cranial nerve injuries after carotid artery surgery. A prospective study of 663 operations. Eur J Vasc Endovasc Surg;10(4): 445-9

[2]. Sajid MS, Vijaynagar B, Singh P, Hamilton G (2007) Literature review of cranial nerve injuries during carotid endarterectomy. Acta Chir Belg;107(1): $25-8$

[3]. Schauber, MD, Fotenelle LJ, Solomon JW, Hanson TL (1997) Cranial/ cervical nerve dysfunction after carotid endarterectomy, Journal of Vascular Surgery; 25 (3): 481-7.

[4]. Ballotta E, Da Giau G, Renon L, Narne S, Saladini M, et al. (1999) Cranial and cervical nerve injuries after carotid endarterectomy: a prospective study. Surgery; 125(1): 85-91

[5]. Assadian A, Senekowitsch C, Pfaffelmeyer N, Assadian O, Ptakovsky H, et al.( 2004) Incidence of cranial nerve injuries after carotid eversion endarterectomy with a transverse skin incision under regional anaesthesia. Eur J VascEndovasc Surg;28(4): 421-4

[6]. Downs AR, Jessen M, Lye CR (1987) Peripheral nerve injuries during carotid endarterectomy. Can J Surg;30: 22-4

[7]. Maniglia AJ, Han DP (1991) Cranial nerve injuries following carotid endarterectomy: an analysis of 336 procedures. Head Neck; 13: 121-4

[8]. Theodotou B, Mahaley M Jr (1985) Injury of the peripheral cranial nerves during carotid endarterectomy. Stroke;16: 894-5

[9]. Szocik JF, Kellogg W, Wakefield TW (1995) Temporary facial nerve palsy during carotid endarterectomy under local anesthesia. AnesthAnalg;81(5): 1106-7 